\title{
A ENFERMAGEM E A ABORDAGEM DA MORTE INFANTIL: UM ESTUDO DE TRABALHOS QUALIS A
}

Yngrid Silveira Dos Santos

Larissa Cruz de Jesus

Graduanda em Enfermagem da Escola Bahiana de Medicina e Saúde Pública.

Graduanda em Enfermagem pela Escola Bahiana de Medicina e Saúde Pública.

\author{
Sandra Dutra Cabral Portella Professora Assistente da Escola Bahiana de \\ Medicina e Saúde Pública. Enfermeira. \\ Mestre pela Universidade Federal do \\ Estado da Bahia.
}

\begin{abstract}
Resumo
Para os profissionais de enfermagem a morte é considerada a maior vilã de seu trabalho, e quando seu paciente é uma criança, a morte é interpretada como uma interrupção do seu ciclo biológico, isso provoca na equipe de enfermagem sentimentos negativos. Assim, os profissionais necessitam estar preparados para receber e cuidar dessas crianças e suas famílias, precisando compreender as reações e comportamentos que eles expõem diante o processo da morte. Este estudo, foi realizado a partir da pesquisa bibliográfica, teve como objetivo investigar estudos científicos que tratem da abordagem da enfermagem sobre a morte infantil com análise de trabalhos Qualis A. O levantamento dos artigos considerou-se publicações entre o período de 2005 a 2011. Os resultados e discussão deste estudo foram organizados e dispostos em uma tabela e diagrama, sendo este representado pelo núcleo central, Morte infantil e Enfermagem, distribuída em três categorias: Enfermagem com a criança no final da vida, Enfermagem com a família e a Enfermagem com a temática morte. Concluiu-se que são necessários estudos futuros que problematizem a possível dissociáveis semântica entre o tema morte infantil na enfermagem.
\end{abstract}

Palavras-chave: Morte; Criança; Enfermagem.

\section{NURSING AND APPROACH OF INFANT DEATH: A STUDY OF WORK QUALIS A}

\begin{abstract}
For nursing professionals death is considered his greatest villain of his work, and when your patient is a child, the death is seen as a disruption of their life cycle, this results in negative feelings nursing staff. Thus, professionals need to be prepared to receive and care for these children and their families need to understand the reactions and behaviors that expose them before the death process. This study was carried out from the literature, aimed to investigate scientific studies dealing with the approach of nursing on the infant death with analysis work Qualis A. The survey of articles considered publications from the period 2005-2011. The results and discussion of this study were organized and arranged in a table and diagram, which is represented by the core, Death and Infant Nursing, distributed in three categories: Nursing with the child at the end of life, Nursing and Family Nursing with theme death. It was concluded that future studies are needed that problematize the possible semantic separable from the subject in nursing infant death.
\end{abstract}

Keywords: Death; Child; Nursing.

\section{ENFERMEÍA Y EL ENFOQUE DE LA MUERTE INFANTIL: UN ESTUDIO DE QUALIS TRABAJO}

\section{Resumen}

Para los profesionales de enfermería la muerte es considerada el mayor villano de su trabajo, y cuando el paciente es un niño, la muerte es vista como una interrupción del ciclo biológico, provocando sentimientos negativos en el equipo de enfermería. Por lo tanto, los profesionales deben estar preparados para recibir y atender a estos niños y sus familias, buscando entender las reacciones y comportamientos a los que se ven expuestos ante el proceso de la muerte. Este estudio se llevó a cabo a partir de la literatura bibliográfica y tuvo como objetivo la investigación de los estudios científicos relacionados con el enfoque de la enfermería en la mortalidad infantil, con análisis del trabajo "Qualis A". Para la elección de los articulos a seren estudiados, fueron consideradas las publicaciones del periodo 2005-2011 . Los resultados 
y la discusión de este estudio fueron organizados y dispuestos en una tabla y en un diagrama , que está representado por el núcleo central, que es la muerte infantil y la enfermería, distribuída en tres categorías : enfermería con el niño al final de la vida, enfermería familiar y enfermería con tema de la muerte . Se concluye que son necesarios estudios futuros que cuestionen la posible disociación semántica entre el tema de la muerte infantil en la enfermería.

Palabras clave: Muerte; Niño; Enfermería.

\section{INTRODUÇÃO}

Uma parte inevitável da vida é seu fim, falar da morte é uma questão difícil de ser entendida, enfrentada e pesquisada. Especialmente em países ocidentais a morte é pouco discutida pela sociedade, tornando-se um tabu. Embora a morte seja um fato natural e certo na vida de todo ser humano (nascer, crescer, morrer); cientificamente, porém aceitar que nossa existência tem um prazo de validade é doloroso.

Quando a palavra "morte" é pronunciada arrebata expressões de espanto, inclusive de enfermeiros e outros profissionais de saúde, buscando várias maneiras de ocultá-la, até mesmo substituindo a palavra morte por diversos sinônimos, como falecimento, óbito, alta celestial, entre outros. ${ }^{(1)}$

Assim, encarar a morte é algo complexo, pois não pensamos em nossa própria morte e não somos capazes de enfrentar essa possibilidade. Lidar com a dor da perda de um ente querido traz à tona seu próprio medo da morte, precisamos compreender e trabalhar nossos próprios sentimentos em relação a isso. Ainda mais quando a morte é de uma criança, pois o natural e mais fácil de ser aceito é que os mais velhos morram antes dos mais dos jovens, que os pais morram antes dos filhos.

Para os pais, um dos principais impactos no cotidiano de suas vidas é quando se deparam com seu filho em fase terminal, pois, quando se tem um filho espera-se que ele cresça, tenha uma profissão, seja independente, tenha um longo caminho a ser percorrido na vida. De repente, todos esses sonhos são esquecidos e o que resta da vida é transformado em luto, diante da grave condição da criança.

A presença dos familiares é de fundamental importância nesse processo, pois para a criança isto é visto como um suporte, ajudando para uma melhor adesão ao tratamento. No entanto, ao cuidar da criança durante o processo de morte, torna-se essencial contemplar os pais, pois essa experiência é vivenciada profundamente por todo sistema familiar.

A enfermagem é uma profissão direcionada ao cuidar e interage com o ser humano desde o nascimento até o processo da morte, é quem permanece maior tempo 
em contato com os pacientes, pois suas ações não se restringem aos procedimentos meramente técnicos e sim, buscam aliar e contemplar suas diversas especialidades. Ao ter uma proximidade com a pessoa doente em iminência de morte, corre-se o risco de se envolver e causar sentimentos negativos como tristeza, frustração, raiva e fuga por não conseguirem manter a vida. ${ }^{(2)}$

Contudo, a formação acadêmica dos profissionais de saúde, inclusive o da enfermagem, ainda é direcionada e posicionada no cuidar para a prevenção, promoção, recuperação e preservação da vida. Assim, muitos profissionais de enfermagem sentemse despreparados para lidarem com situações que envolvem a morte, devido a essa ausência de reflexão e total silêncio, por parte da instituição acadêmica, na qual seguem normas e condutas objetivando ao tecnicismo de salvar vidas, acreditando que a vivência possa levar os profissionais a descobrirem o que é relevante neste processo. ${ }^{(2)}$

Dessa forma, é importante considerar a necessidade de pesquisas, que identifiquem o significado da experiência de morte para a enfermeira que trabalha na área de pediatria, como possibilidade de elaborar a perda e encontrar energia para reinvestir em relacionamentos com outras crianças, mesmo aquelas que estão morrendo. ${ }^{(3)}$

A fragilidade da habilidade da enfermagem para o enfrentamento da morte da criança pela equipe tem-se mostrado um fator negativo, impedindo o bom andamento do serviço de enfermagem. Por ser um evento corriqueiro na prática da enfermagem, a morte deveria ser melhor entendida e trabalhada por esta equipe. ${ }^{(4)}$ Considera-se a morte de uma criança a mais traumática para uma equipe, ${ }^{(5)}$ justificando-se, portanto a elaboração deste trabalho, que alimente apontamentos, que intuem um trabalho melhor para as ações de enfermagem nos momentos de morte das crianças com quem convivem e executa suas tarefas. Diante do exposto, o objetivo foi investigar estudos científicos que tratem da abordagem da enfermagem sobre a morte infantil com análise de trabalhos Qualis A.

\section{METODOLOGIA}

Para elaboração do presente estudo, realizou-se uma revisão bibliográfica, através de registro disponível, decorrente de pesquisas anteriores, em documentos impressos, como livros, artigos, teses etc. Utiliza-se de dados ou de categorias teóricas já trabalhadas por outros pesquisadores e devidamente registrados. O pesquisador 
trabalha a partir das contribuições dos autores dos estudos analíticos constantes dos textos. ${ }^{(6)}$

Outros autores revelam que a pesquisa bibliográfica não é a mera repetição do que já foi dito ou escrito sobre certo assunto, mas novo enfoque ou abordagem, chegando a conclusões inovadoras. ${ }^{(7)}$

Foram rastreados trabalhos científicos, em duas etapas, a fim de tornar-se o estudo único. A primeira etapa utilizou-se o vocabulário estruturado e trilíngue, Descritores em Ciências da Saúde (Decs), que serviu como linguagem única da indexação e artigos de revistas científicas. Para a temática sobre Morte Infantil e Enfermagem, selecionamos o descritor Morte pelo Decs, a partir disto foi selecionado a nota de indexação descrito como Tanatologia, onde encontramos 356 artigos, que posteriormente refinou-se com a palavra Enfermagem, reduziu-se o quantitativo para 46 artigos, destes optamos por apenas 10 artigos. A base de dados selecionada foi: Medline (Literatura Internacional em Ciências da Saúde).

A segunda etapa foi realizado um aprofundamento de mais pesquisas, no Portal da Coordenação de Aperfeiçoamento de Pessoal de Nível Superior (Capes), devido a escassez de artigos específicos relacionados a morte infantil, utilizando as seguintes palavras-chave combinadas: Morte, Enfermagem e Criança. A partir disto encontramos 73 artigos, deste quantitativo optamos por 7 artigos para este trabalho. Foram, para tanto, acessados os conteúdos das bases de dados: Scielo Brazil (Scientific Electronic Library Online) e Cegance Learning, Inc. Portanto 17 artigos compõem esta revisão.

Em seguida, traçaram-se os critérios de inclusão para os artigos científicos, definiu-se: que os trabalhos estivessem na íntegra, de acordo com o objetivo do estudo, trabalhos estivessem disponíveis gratuitamente, trabalhos dentro dos critérios exigidos pelos Capes, que estratifica a qualidade do produto intelectual dos programas de pósgraduação, sendo assim, este afere a qualidade dos artigos, que tivessem o indicativo de qualidade A1 e A2, considerados os mais elevados e apenas artigos que retratassem o assunto morte e enfermagem, morte, criança e enfermagem. A busca foi delimitada também pela língua, utilizando apenas as línguas portuguesa, inglesa e espanhola. Como critério de exclusão definiu-se: todos os artigos que não respondessem aos critérios de inclusão.

O levantamento dos artigos considerou publicações entre o período de 2005 a 2011. Favorecendo os parâmetros de pesquisa na atualidade. Tem-se a clareza de que esta pesquisa não contempla todas as publicações brasileiras e internacionais sobre a 
temática. Contudo, a análise dos textos nacionais e internacionais possibilitou traçar um panorama aprofundado e extensivo da temática e mapear o estado da arte da produção científica da Enfermagem acerca da perda da criança. Tratando-se de uma pesquisa bibliográfica, não foi necessário submeter ao Comitê de ética.

Em cada uma dessas buscas (Decs e Capes), obtivemos um total de 17 artigos e, a partir de então, iniciamos as leituras dos resumos selecionados, depois realizamos síntese dos dados, contemplando título, autores, revistas de Qualis A, ano de publicação, metodologia, resultados e conclusões. Em seguida, efetuaram-se os fichamentos para a coleta de dados. Com vistas a facilitar a panorâmica bibliográfica desta pesquisa e seu nível de qualidade foi criada, inicialmente, um quadro que representasse melhor os 17 artigos. Este quadro descreveu; Perfil dos artigos publicados descrevendo: autores, título do artigo, periódicos, indicativo de qualidade pelo Capes e ano de publicação para demonstração. Em seguida, no resultado e discussão, construímos a Figura 1 - Diagrama representativo das categorias e subcategorias, segundo as bases de dados, o que contribuiu para a análise das categorias e subcategorias. Optou-se para esta fase uma discussão analítica com base nos autores inseridos no estudo.

Quadro 1 - Perfil dos artigos publicados. A tabela descreve: autores, título do artigo, periódicos, indicativo de qualidade pelo CAPES e ano de publicação.

\begin{tabular}{|c|c|c|c|c|}
\hline Autores & Título do artigo & Periódicos & $\begin{array}{l}\text { Nível de } \\
\text { qualidade } \\
\text { de estudo }\end{array}$ & $\begin{array}{c}\text { Ano de } \\
\text { publicação }\end{array}$ \\
\hline $\begin{array}{l}\text { Junior FJGS, Santos LCS, } \\
\text { Moura PVS, Melo BMS, } \\
\text { Monteiro CFS }\end{array}$ & $\begin{array}{l}\text { Processo de morte e morrer: evidências da } \\
\text { literatura científica de Enfermagem }\end{array}$ & $\begin{array}{l}\text { Rev. Bras. } \\
\text { Enfermagem }\end{array}$ & $\mathrm{A} 2$ & 2011 \\
\hline Santos JL, Bueno SMV & $\begin{array}{l}\text { Educação para a morte a docentes e discentes } \\
\text { de enfermagem: revisão documental da } \\
\text { literatura científica }\end{array}$ & $\begin{array}{l}\text { Rev. Escola de } \\
\text { Enfermagem da } \\
\text { USP }\end{array}$ & $\mathrm{A} 2$ & 2011 \\
\hline $\begin{array}{l}\text { Bousso RS, Poles K, } \\
\text { Serafim TS, Miranda MG }\end{array}$ & $\begin{array}{l}\text { Crenças religiosas, doença e morte: perspectiva } \\
\text { da família na experiência de doença }\end{array}$ & $\begin{array}{l}\text { Rev. Escola de } \\
\text { Enfermagem da } \\
\text { USP }\end{array}$ & $\mathrm{A} 2$ & 2011 \\
\hline $\begin{array}{l}\text { Oliveira SG, Quintana } \\
\text { AM, Bertolino KCO }\end{array}$ & $\begin{array}{l}\text { Reflexões acerca da morte: um desafio para a } \\
\text { enfermagem }\end{array}$ & $\begin{array}{l}\text { Rev. Bras. } \\
\text { Enfermagem }\end{array}$ & $\mathrm{A} 2$ & 2010 \\
\hline
\end{tabular}




\begin{tabular}{|c|c|c|c|c|}
\hline $\begin{array}{l}\text { Bousso RS, Serafim TS, } \\
\text { Misko MD }\end{array}$ & $\begin{array}{l}\text { Histórias de vida de familiares de crianças com } \\
\text { doenças graves: relação entre religião, doença } \\
\text { e morte }\end{array}$ & $\begin{array}{l}\text { Rev. Latino - } \\
\text { Americano de } \\
\text { Enfermagem }\end{array}$ & A1 & 2010 \\
\hline $\begin{array}{l}\text { Silva LCSP, Valença CN, } \\
\text { Germano RM }\end{array}$ & $\begin{array}{l}\text { Estudo fenomenológico sobre a vivência da } \\
\text { morte em uma unidade de terapia intensiva } \\
\text { neonatal }\end{array}$ & $\begin{array}{l}\text { Rev Bras } \\
\text { Enfermagem }\end{array}$ & $\mathrm{A} 2$ & 2010 \\
\hline $\begin{array}{l}\text { Bousso RS, Poles K, } \\
\text { Rossato, LM }\end{array}$ & $\begin{array}{l}\text { Desenvolvimento de conceitos: novas direções } \\
\text { para a pesquisa em tanatologia e enfermagem }\end{array}$ & $\begin{array}{l}\text { Rev. Escola de } \\
\text { Enfermagem da } \\
\text { USP }\end{array}$ & $\mathrm{A} 2$ & 2009 \\
\hline Poles K, Bousso RS & Morte digna da criança: análise de conceitos & $\begin{array}{l}\text { Rev. Escola de } \\
\text { Enfermagem da } \\
\text { USP }\end{array}$ & $\mathrm{A} 2$ & 2009 \\
\hline $\begin{array}{l}\text { Silva KS, Ribeiro RG, } \\
\text { Kruse MHL }\end{array}$ & $\begin{array}{l}\text { Discursos de enfermeiras sobre morte e } \\
\text { morrer: vontade ou verdade? }\end{array}$ & $\begin{array}{l}\text { Rev Bras } \\
\text { Enfermagem }\end{array}$ & $\mathrm{A} 2$ & 2009 \\
\hline $\begin{array}{l}\text { Salomé GM, Cavali A, } \\
\text { Espósito VHC }\end{array}$ & $\begin{array}{l}\text { Sala de Emergência: o cotidiano das vivências } \\
\text { com a morte e o morrer pelos profissionais de } \\
\text { saúde }\end{array}$ & $\begin{array}{l}\text { Rev Bras } \\
\text { Enfermagem }\end{array}$ & $\mathrm{A} 2$ & 2009 \\
\hline Moreira PL, Angelo M & $\begin{array}{l}\text { Tornar-se mãe de criança com câncer: } \\
\text { construindo a parentalidade }\end{array}$ & $\begin{array}{l}\text { Rev. Latino - } \\
\text { Americano de } \\
\text { Enfermagem }\end{array}$ & A1 & 2008 \\
\hline $\begin{array}{l}\text { Oliveira JR, Brêtas JRS, } \\
\text { Yamaguti L }\end{array}$ & $\begin{array}{l}\text { A morte e o morrer segundo representações de } \\
\text { estudantes de enfermagem }\end{array}$ & $\begin{array}{l}\text { Rev. Escola de } \\
\text { Enfermagem da } \\
\text { USP }\end{array}$ & $\mathrm{A} 2$ & 2007 \\
\hline $\begin{array}{l}\text { Santana MTBM, Jorge } \\
\text { MSB }\end{array}$ & $\begin{array}{l}\text { Corpo próprio como experiência vivencial da } \\
\text { enfermeira no cuidar do outro no processo de } \\
\text { morrer }\end{array}$ & $\begin{array}{l}\text { Rev. Latino - } \\
\text { Americano de } \\
\text { Enfermagem }\end{array}$ & A1 & 2007 \\
\hline Poles K, Bousso RS & $\begin{array}{l}\text { Compartilhando o processo de morte com a } \\
\text { família: a experiência da enfermeira na UTI } \\
\text { pediátrica }\end{array}$ & $\begin{array}{l}\text { Rev. Latino - } \\
\text { Americano de } \\
\text { Enfermagem }\end{array}$ & A1 & 2006 \\
\hline Bolze DAS, Castoldi L & $\begin{array}{l}\text { O acompanhamento familiar antes e depois da } \\
\text { morte da criança: uma proposta de intervenção } \\
\text { para o psicólogo hospitalar }\end{array}$ & Aletheia & A1 & 2005 \\
\hline Costa JC, Lima RAG & $\begin{array}{l}\text { Luto da equipe: revelações dos profissionais de } \\
\text { enfermagem sobre o cuidado à } \\
\text { criança/adolescente no processo de morte e } \\
\text { morrer }\end{array}$ & $\begin{array}{l}\text { Rev. Latino - } \\
\text { Americano de } \\
\text { Enfermagem }\end{array}$ & A1 & 2005 \\
\hline
\end{tabular}




\begin{tabular}{|l|l|l|l|l|}
\hline Nascimento LC, Rocha & Crianças com câncer e suas famílias & Rev. Escola de & \\
SMM, Hayes VH, Lima & & Enfermagem da & A2 \\
AG & & USP & \\
\hline
\end{tabular}

Fonte: Elaborada pelas autoras com base em dados bibliográficos (2013).

\section{RESULTADO \& DISCUSSÃO}

O diagrama esta representado pelo núcleo central temático - Morte infantil e Enfermagem - gerando três categorias: Enfermagem com a criança no final da vida, Enfermagem com a família e Enfermagem com a temática morte. A categoria Enfermagem com a criança no final da vida apresenta três subcategorias, a saber: $\underline{\text { Sentimentos do enfermeiro, }}$ Abordagem profissional e Assistência singular da enfermagem. A Enfermagem com a família apresenta três subcategorias também:

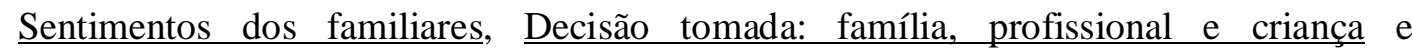
Comunicação da morte com a criança e/ou família. Já a Enfermagem com a morte apresentou cinco subcategorias: $\underline{\text { Crença e religião, }}$ Morte digna, Despreparo acadêmico e profissional, Amparo profissional e Literatura de enfermagem sobre morte. A seguir o diagrama representado (Figura 1).

Figura 1 - Diagrama representativo das categorias e subcategorias, segundo as bases de dados

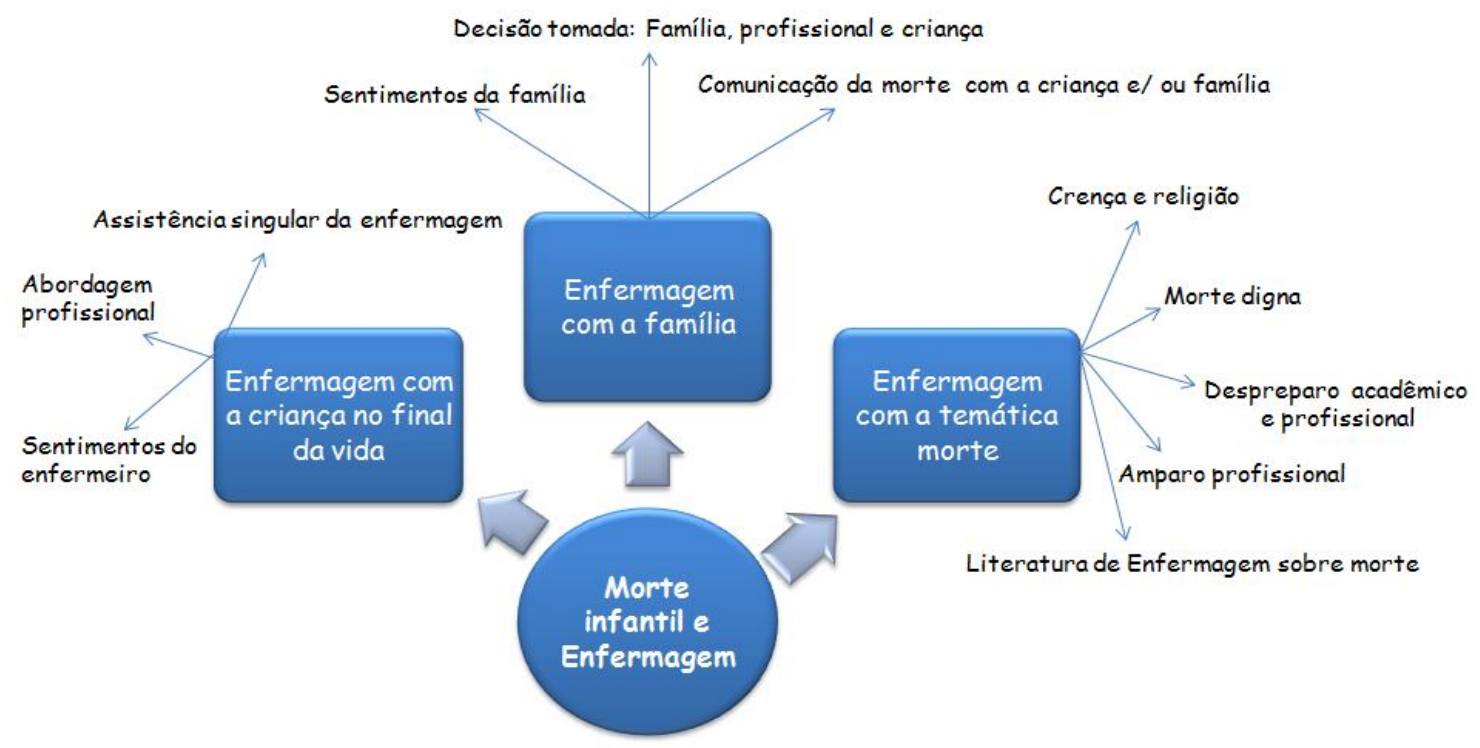

Fonte: Elaborada pelas autoras com base em dados bibliográficos (2013). 
Sobre o núcleo temático Morte infantil e Enfermagem é verificado pela literatura que o processo de morrer de uma criança causa grande impacto na vida profissional de toda a equipe de enfermagem, sendo visto como a maior vilã a ser enfrentada por cada membro da equipe de saúde, tentando assim aprender a lidar com essas ocasiões que fazem parte do dia-a-dia no hospital. Há um grande número de pacientes, entre eles crianças, com condição grave e em fase avançada, sendo constante a morte. Assim, a enfermagem necessita estar preparada para receber e cuidar dessas crianças, precisando perceber os sentimentos que eles revelam perante a morte, assistindo-os em suas necessidades durante o processo de finitude. É notório que ao constatar o medo da morte de uma criança, é necessário o apoio emocional não só para a equipe de enfermagem, como também para os familiares. ${ }^{(4,8)}$

\subsection{CATEGORIA 1: ENFERMAGEM COM A CRIANÇA NO FINAL DA VIDA}

Esta categoria foi criada em virtude dos estudos selecionados que apresentam como repercussão a experiência das enfermeiras que cuidam da criança que vivencia o processo de morte. Isto possibilitou identificar fatores que interferem na aproximação e/ou afastamento da criança nesse momento particular. A manifestação de dificuldades e facilidades da enfermagem em lidar com a morte infantil, na qual são pautadas a interação e visões diante de suas experiências vividas. Se deparar com a morte da criança assistida, remete para muitos profissionais, atalhos e impedimentos que compõem o contexto desta realidade. No caso da fase terminal, esta é considerada uma situação individual para o profissional de enfermagem, pois as questões relacionadas às perdas reais ou possíveis e o medo da própria terminalidade, ocasiona uma espécie de proteção como mecanismo de defesa. ${ }^{(3)}$

\section{- $\quad$ Sentimentos do enfermeiro}

Os estudos revelam que os sentimentos são negativos: medo, perda, sofrimento, angustia, frieza, dor, fracasso e erro. Durante o exercício da profissão, os enfermeiros seguem normas e condutas objetivando salvar vidas e evitar a morte, que, quando se faz presente, pode causar um estado de tristeza, perda, frustração e estresse já que ver o corpo inerte de uma pessoa para o qual se prestou cuidados, se dedicou tempo, energia, carinho, amor, se trocou palavras e até mesmo se riu lado a lado é algo que causa estranheza. $^{(9,10)}$

Revista Enfermagem Contemporânea. 2013 Ago;2(1):112-130. 
Compreende-se que a equipe de enfermagem, é quem geralmente está próximo nos momentos difíceis, onde os pacientes buscam quando necessitam de esclarecimentos, ou de cuidados imediatos. Em diversas situações que envolvem o cuidar, até mesmo com a morte, os profissionais tem que saber lidar com esses sentimentos negativos, saber também, transmitir segurança e desenvolver suas funções adequadas no seu ambiente de trabalho. Observamos que alguns profissionais não estão se permitindo viver esta situação, protegendo-se como um mecanismo de defesa. Portanto, para estes a morte é considerada um insucesso do tratamento e um fracasso da equipe, levando a enfermeira a limitar ao máximo o contato com o paciente e sua família, evitando conversas e dedicando-se em intensas atividades e em um perfeccionismo técnico.

\section{- $\quad$ Abordagem profissional}

Diz respeito à importância do trabalho conjunto em equipe multidisciplinar, que inclui: médico, enfermeira, assistente social, psicólogo e consultor espiritual, onde todos os membros da equipe participam nas condutas e decisões relacionadas à criança fora de possibilidades terapêuticas de cura. As questões éticas de cada paciente devem ser discutidas entre toda a equipe que assiste o paciente. $^{(8)}$

É evidente na literatura que a enfermagem e os profissionais de saúde devem planejar clara sobre o tema morte, tanto para as crianças quanto os seus familiares. Quando os profissionais se sentem impotentes, não se habituando a situação de morte acabam não compartilhando suas emoções com seus colegas de trabalho, aumentando ainda mais a tensão. Muitos deles mostram a sua impotência e frustração perante a imprevisibilidade da trajetória da morte, pois o envolvimento é tão grande que o momento de expressar o seu sentimento é a forma de aliviar sua própria dor. É importante ressaltar que ao vivenciar no cotidiano situações de vida e morte, pela equipe de enfermagem, se torna essencial conhecer seus próprios sentimentos e necessidades, livre de aflição e tensão, para que possa assistir melhor os seus pacientes, e portanto, o ambiente estará mais agradável para o trabalho. Dessa forma, é importante trabalhar em equipe, pois a tarefa fica pronta mais rápida, cria-se assim uma união, um convívio harmonioso entre a equipe, uma amizade entre todo o grupo, em virtude de que, o trabalho em equipe sempre beneficiará a todos, os pacientes, os familiares, os colegas de trabalho, fazendo assim, que o sucesso e o objetivo seja sempre alcançado e baseado na ética. $^{(1)}$ 
- $\quad$ Assistência singular do enfermeiro

Acreditamos que uma assistência de qualidade implica uma interação com o paciente, pois é a partir dela que ele identifica as reais necessidades que as crianças/adolescente e suas famílias demandam. ${ }^{(4)}$

Refere-se ao bem-estar da criança na fase final da vida. Para tanto, é necessário que a assistência seja individualizada, fugindo da padronização e protocolos rígidos, atendendo as dimensões biológica, psicológica, social e espiritual da criança. ${ }^{(8)}$

Os estudos demonstram que a enfermagem precisa desenvolver métodos de abordagem que apreendam as suas necessidades de assistência, particularizando o cuidado de acordo com a singularidade de cada caso e evitando estereótipos ou preconceitos, os quais referem-se tanto às incapacidades da criança, quanto às limitações dos pais em encontrarem formas criativas e positivas para lidar com dificuldades no processo de crescimento e desenvolvimento da criança. ${ }^{(11)}$

Os profissionais de saúde que vivenciam a unidade hospitalar reconhecem que existem pacientes especiais, com os quais estabelecem uma relação diferenciada e de qualidade. Para proporcionar uma assistência de enfermagem planejada e individualizada, é necessário que se tenha integração entre as equipes de saúde. Desta forma, cabe ao enfermeiro promover um cuidado centrado na criança de maneira humanizada, com um olhar amplo diante suas limitações, pois é a partir dela que a enfermagem identifica as reais necessidades desta criança. Para tanto, destaca-se outras particularidades individuais, que devem ser levadas em conta, como as culturais e regionais, para que a assistência de enfermagem não seja padronizada durante o manejo do cuidado, como um processo técnico, sem especificidades e particularidades. ${ }^{(11)}$

\subsection{CATEGORIA 2: A ENFERMAGEM COM A FAMÍLIA}

A segunda categoria menciona a vivência dos pais, que se depara com difíceis situações, onde a vida do filho está sob ameaça, além de ser muito complicado tratar da grave condição da criança. Quando uma criança adoece a família também adoece, é impossível pensar na criança sem seus pais. Faz-se necessário destacar que a relação conjugal que fica praticamente vulnerável após a morte de um filho, correndo risco de maior desgaste da satisfação matrimonial ao longo do tempo. É neles que o foco de suas preocupações é em torno da qual todas as suas decisões serão tomadas. Cabe salientar que decidir o tempo da criança é determinar que ela seja o que há de mais importante em

Revista Enfermagem Contemporânea. 2013 Ago;2(1):112-130 
sua existência e na vida da sua família, para que todos se preparem e não se percam para o tempo difícil que está por vir. ${ }^{(5,12)}$

- $\quad$ Sentimentos dos familiares

A perda de uma pessoa amada é uma das experiências mais intensamente dolorosa que o ser humano pode sofrer. ${ }^{(9)}$

Sentimentos de dor, tristeza, angústia, saudade, depressão e dificuldades em continuar vivendo, aos poucos iam dando lugar a uma estabilidade gradual. As lembranças dos momentos difíceis e tristes são substituídas por memórias da vida das crianças como um todo. ${ }^{(1)}$

Retomar o equilíbrio familiar, procurando incorporar a criança à rotina doméstica e tentando adaptá-la ao novo estilo de vida, tem sido um objetivo dos pais. Paralelamente à necessidade de retomar a "normalidade", estes buscam substituir os sentimentos de "incerteza" que permeiam sua experiência, pela "certeza" de que a doença está sob controle ou que está sendo manejada adequadamente. ${ }^{(11)}$

A presença de uma criança enferma a beira da morte, desestrutura todos os membros da família, sendo difícil para os pais aceitar e enfrentar a finitude de seus filhos, resultando no maior impacto no cotidiano de suas vidas. Não se deve também subestimar os sentimentos dos familiares, nem deixá-los desamparados neste momento fúnebre, por serem indivíduos que necessitam de uma atenção especial e precisam de apoio.

Esse fato gera alterações em seus sonhos e esperanças em relação ao futuro dos seus filhos, a partir de então, os pais buscam construir estratégias de enfrentamento da doença. Um exemplo de estratégia é a oração que é vista como uma espécie de conforto que os familiares podem fazer pela criança diante de uma situação de doença grave, sendo uma forma importante de estratégia que ameniza o sofrimento causado pela doença do filho, gerando alívio para os familiares e ajudando seu estado físico e emocional, envolvido com sua criança. É relevante destacar que o elo familiar é fundamental para o processo de hospitalização da criança, pois assim a criança poderá se sentir mais protegida perante os seus medos e receios. ${ }^{(11,13)}$

- Decisão tomada: família, profissional e criança

O suporte à família se dá quando há entendimento e aceitação de qualquer decisão que os pais tomem. A comunicação clara e efetiva é o atributo mais importante do processo de tomada de decisão durante a fase terminal. ${ }^{(14)}$

A hora da verdade inevitavelmente chega, quando a equipe e a família precisam tomar uma decisão, permitindo que o paciente morra dignamente, sem futuras intervenções para prolongar a vida, o que na realidade só postergará a morte. ${ }^{(8)}$

Revista Enfermagem Contemporânea. 2013 Ago;2(1):112-130. 
A participação da família nas tomadas de decisão e sua presença durante o processo de morrer é vista cada vez mais com maior naturalidade. No entanto, muitos estudos destacam a necessidade dos médicos e enfermeiras de melhorar suas habilidades de comunicação com as famílias, especialmente durante o processo de morrer. ${ }^{(8)}$

A inclusão da família nas decisões de final de vida, inclusão dos pais nas discussões/reuniões de equipe, bem como o envolvimento da criança nas decisões quando possível, isto é, quando ela estiver consciente e seu nível de desenvolvimento cognitivo permita a sua participação. ${ }^{(8)}$

É importante considerar a participação do enfermeiro junto à equipe multiprofissional, para que seja possível proporcionar uma decisão mais aperfeiçoada, quanto à utilização das formas terapêuticas de comunicação, esclarecimento sobre o diagnóstico, evolução e tratamento da criança, bem como explicações sobre as rotinas da unidade. É necessária que toda a equipe esteja envolvida e ciente do quadro de saúde do paciente, assim a informação fluirá para a família de forma igual. Além disso, é importante compartilhar com os pais a responsabilidade na decisão da morte da criança, permitindo assim uma morte digna.

\section{- Comunicação da morte com a criança e/ou família}

Inclui a comunicação aberta com a criança fora de possibilidades terapêuticas de cura e sua família, através de informações verdadeiras, honestas e congruentes entre toda a equipe de saúde. É, também, de extrema importância explicações sobre os detalhes da doença, tratamento e cuidados de forma simples e acessível. Além disso, os profissionais de saúde necessitam de habilidade para comunicar-se com a criança em final de vida, de acordo com sua idade e nível de desenvolvimento cognitivo, bem como habilidade para comunicar más notícias para a família. ${ }^{(8)}$

É necessário que os médicos e enfermeiros tenham habilidades para comunicar más notícias, melhorando a relação e comunicação com as famílias e os pacientes em fase terminal. ${ }^{(8)}$

Entende-se que os profissionais de saúde encaram a transmissão de más notícias, pela complexidade do assunto, envolvendo reações emocionais e requer treinamento, exigindo assim que desenvolvam competências e técnicas, deve-se lembrar que essa comunicação precisa ser feita em ambientes tranquilos e reservados. Ressalte-se ainda que, tanto o desempenho verbal, como o não verbal emitido na interação entre profissional-paciente-família, faz parte do que se denomina a comunicação. ${ }^{(8)}$ Emergindo uma comunicação efetiva, os profissionais prestam uma assistência de forma holística, no intuito de permitir à sua clientela o entendimento e enfrentamento dos agravos, não deixando de restabelecer o bem-estar geral. Compreende-se que devem ser capazes de assegurar as mensagens emitidas e de interpretá-las, buscando uma 
particularidade e necessidade de cada indivíduo, a fim de estabelecer um relacionamento aberto de confiança e respeito recíproco.

\subsection{CATEGORIA 3: ENFERMAGEM COM A TEMÁTICA MORTE}

Nessa categoria, percebemos que durante o exercício da profissão dos enfermeiros a compreensão da morte de cada paciente deve ser vista como um acontecimento único, não devendo o profissional de enfermagem se desestruturar a cada evento que essa situação aconteça. Nas situações vivenciadas pela equipe, é proporcionado tanto satisfação e prazer, quanto desgaste e sofrimento. Sendo o prazer, quando o tratamento é bem-sucedido, já o desgaste aparece muitas vezes estampado no rosto ou nas expressões verbais dos profissionais, principalmente quando o processo de morte é prolongado. ${ }^{(4)}$

\section{- $\quad$ Crença e religião}

A religião oferece suporte emocional e social, motivação, recursos de cuidado à saúde e promove estilos de vida mais saudáveis. Neste sentido, os profissionais de saúde precisam conhecer as crenças que tornam o paciente e seus familiares mais, ou menos, dispostos a receber o tratamento. ${ }^{(15)}$

A religião é um instrumento de explicações que ajudam a dar significado às experiências de doença e morte. A espiritualidade, religiosidade ou crenças religiosas mostram- se condutoras dos comportamentos dos familiares ao se moverem para um estado de adaptação e ajustamento à doença e morte. ${ }^{(15)}$

Estudos revelam que, a presença da religião tem se mostrado importante no cotidiano na vida das pessoas, através dela emerge práticas e representações dos cuidados com o corpo, que merecem ser compreendidas na atenção e saúde, pois oferecem suporte emocional, espiritual e social para todo o doente e sua família. Socializando e dirigindo os cultos de morte de forma mais delicada para lidar com o receio. Ressalta-se ainda, que é necessário que a enfermagem valorize os seus clientes como seres que pensam e sentem e que podem gerenciar suas próprias vidas, não deixando de respeitar as crenças e religiões dos pacientes e suas famílias. Assim sendo, os profissionais de enfermagem precisam conhecer e valorizar a espiritualidade que faz parte do ser humano independente de crenças, respeitando a presença da família nesse repertório durante o processo do cuidado com estas crianças. ${ }^{(5,9,13,15)}$ 


\section{- $\quad$ Morte digna}

Vários autores apontam o interesse crescente pelas questões relacionadas ao fim da vida a partir dos anos 90, com o surgimento de discussões acerca da manutenção da vida a qualquer custo e da bioética em um contexto de exponencial crescimento científico, onde o uso da tecnologia resulta em conflitos com os limites terapêuticos. ${ }^{(8)}$

Quando ocorre a morte digna, observa-se a preservação da autonomia do paciente e da família, que devem ter o direito de decidir por aceitar, ou não, determinada intervenção terapêutica, garantindo que a assistência recebida esteja de acordo com as preferências do paciente e/ou da família. ${ }^{(8)}$

Na Resolução do CONANDA - O Conselho Nacional dos Direitos da Criança e do Adolescente, $n^{\circ} 41$ de 17 de outubro de 1995, enfatiza os direitos da Criança e do Adolescente Hospitalizados, afere no artigo $20^{\circ}$, o direito a ter uma morte digna deve ser junto a seus familiares, quando esgotados todos os recursos terapêuticos disponíveis. ${ }^{(16)}$

Segundo a LEI ESTADUAL No 10.241, de 17 de março de 1999, dispõe sobre os direitos dos usuários dos serviços e das ações de saúde no Estado e dá outras providências. Referindo no Artigo $2^{\circ}$ - Direitos dos usuários dos serviços de saúde ter um atendimento digno, atencioso e respeitoso; receber ou recusar assistência moral, psicológica, social ou religiosa; recusar tratamentos dolorosos ou extraordinários para tentar prolongar a vida e optar pelo local de morte. ${ }^{(17)}$

As literaturas relatam que Morrer dignamente é o sonho de todo indivíduo, é um desafio para os profissionais de saúde, pois envolve o equilíbrio de múltiplas perspectivas e necessidades da criança, da família e da própria equipe, trazendo alívio dos sofrimentos. O profissional precisa ter uma compreensão clara sobre o conceito de morte digna, para poder promover o processo de morrer da criança, sendo respaldado pela Lei Estadual no 10.241 e Resolução Conanda nº 41 de 17 de outubro de 1995.

Acredita-se que trabalhar com crianças em iminência de morte não seja um trabalho fácil. Para propor uma assistência que atenda às necessidades das crianças, o profissional precisa ter consciência e compreensão do que necessita oferecer. Para proporcionar o conforto à criança, a enfermagem busca estratégias farmacológicas ou não farmacológicas, tais como: musicoterapia, uso de compressas, massagens e relaxamento que cessem ou, pelo menos, aliviem a dor física e o desconforto físico, como: constipação, náusea, vômito ou dispneia, para que seu sofrimento seja o menor possível.

O profissional de enfermagem segue como referência os princípios empregados nos cuidados paliativos. Contudo o enfermeiro vê-se perante um dilema, entre aquilo que ele acredita ser a melhor conduta a seguir, e a resposta legal de seus atos, identificando não só ações intrínsecas para uma promoção da morte digna, tais como: 
maturidade do profissional e significado que confere à morte, como também ações extrínsecas, que demonstram autonomia e conforto. ${ }^{(1,8)}$

\section{- Despreparo acadêmico e profissional}

Ao ingressar na Universidade os acadêmicos de enfermagem enfrentam suas primeiras experiências relacionadas á morte nas aulas de anatomia, que apesar de causarem desconforto, são poucas discutidas. ${ }^{(18)}$

As propostas de melhora devem estar voltadas para as instituições de formação. As mudanças necessitam ocorrer simultaneamente nas escolas e nas instituições hospitalares, ou seja, as escolas deveriam preparar seus alunos para atuarem com a vida e a morte nos hospitais, enquanto que as instituições hospitalares poderiam, com o auxílio da educação permanente, ajudar os profissionais a realizarem reflexões sobre o luto. ${ }^{(4)}$

Verificou-se ainda, a necessidade da produção e publicação de mais estudos sobre a temática da Morte. Ressaltando ainda a urgência na introdução de uma visão crítico-reflexiva para o processo de morte e morrer na formação acadêmica, a fim de estes profissionais sejam capazes de aceitar a Morte, quando inevitável, de uma forma mais natural, desvinculando - a assim, da denotação de fracasso e frustração pessoais. ${ }^{(14)}$

E que apesar de algumas universidades oferecerem disciplinas que abordam a temática da Morte, todos os estudos demonstraram que os alunos carecem de reflexão e discussão. ${ }^{(14)}$

Consta-se que os discentes de Enfermagem apresentam dificuldades em enfrentar a morte, desde a sua formação acadêmica, por diversos motivos, como a falta de habilidade, a incapacidade de aceitar, carência de informação, cultura e por ser uma experiência dolorosa. Esse despreparo vem muitas vezes da sua própria bagagem de vida, pois outro elemento que merece destaque é a dificuldade dos estudantes em enfrentar a morte dos seus familiares. Na maioria das instituições de ensino, a temática da morte e sua vivência são de certa forma, relegadas ou excluídas da formação dos estudantes, não existindo uma disciplina específica sobre a temática que ressalte a esfera humanística e filosófica, dando a impressão de que somente o restabelecimento da saúde, faz parte de uma boa assistência. E que mesmo algumas universidades que oferecem disciplinas que abordam a Morte, existem estudos que comprovam que os alunos carecem de reflexão e discussão, a fim de se desnudarem dos pré-conceitos socioculturais ocidentais vividos na infância. É notório que muitos profissionais de enfermagem sentem dificuldade ainda hoje em lidar com este tema, devido a esse déficit de reflexões e total silêncio, por parte das academias, que dão importância ao tecnicismo, confiando na hipótese de que os enfermeiros podem tentar suprir suas falhas, no dia-a-dia do exercício da profissão, através das experiências vividas. ${ }^{(2,9,14)}$ 


\section{- Amparo profissional}

Os profissionais de enfermagem estão sofrendo e estão sozinhos nessa batalha travada entre a vida e a morte. Precisamos ajudá-los a compreender a morte como uma etapa que precisa ser vivida e, também, ajudá-los a compreender o seu luto como sendo uma resposta necessária à perda e à morte de crianças/adolescentes que estavam sob seus cuidados. ${ }^{(4)}$

Verificou-se que através dos artigos lidos e analisados por estas autoras, existe uma escassez de informações a respeito do amparo aos profissionais de Enfermagem e mesmo assim, pôde-se perceber através dos depoimentos dos profissionais, nas pesquisas de campo, que esta subentendida a sua necessidade. Contudo, sabe-se que existem publicações que abordam está problemática. Evidenciou-se assim que se precisa de um apoio psicológico diante deste problema, para que o profissional possa desabafar, expressar suas emoções e servir como o desenvolvimento de estratégias de enfrentamento que variam de acordo com a realidade vivida por cada profissional que presencia a morte. Existe também uma necessidade por parte dos profissionais em buscar atividades alternativas, de lazer, para evitar o cansaço, a depressão, como uma "válvula de escape".(19)

\section{- $\quad$ Literatura de Enfermagem sobre morte}

Embora a qualidade dos cuidados no final de vida seja amplamente estudada em adultos, ainda existem poucos estudos sobre a morte de crianças. Além disso, as diferentes percepções dos profissionais de saúde sobre a qualidade do cuidado durante o processo de morrer não estão claras. ${ }^{(8)}$

As publicações das enfermeiras acerca da temática, a partir dos anos dois mil, aumentam bruscamente, e em cinco anos, o número de artigos publicados é quase igual ao das sete décadas anteriores. ${ }^{(18)}$

A maioria dos estudos analisados foi publicado na área médica e apenas alguns na área da enfermagem, evidenciando que a temática ainda é escassamente explorada no âmbito da enfermagem. ${ }^{(8)}$

Nota-se a necessidade de mais publicações a respeito da morte, junto à enfermagem, averiguou-se que existem poucos estudos voltados para esta temática e que mesmo com um quantitativo pouco, houve um crescimento absurdo de publicações, a partir dos anos dois mil e ainda assim, com este aumento há uma escassez de pesquisas, sobre o tema. A literatura sinaliza que os estudos mais publicados estão voltados à morte em adulto, e poucas retratam a morte da criança. Acreditamos que seja uma 
consequência da dificuldade em abordar e refletir a morte infantil, pelos profissionais de saúde.

\section{CONSIDERAÇÕES FINAIS}

A revisão relacionada sobre a abordagem da enfermagem diante da morte infantil, refere que os profissionais de enfermagem e os estudantes sentem-se despreparados para lidar com essa situação devido à falta de estudos e reflexões que abordem o tema. É observado que apenas na vivencia cotidiana diante da morte é que realmente os profissionais estão adquirindo experiência. Estes significados são estabelecidos ao longo de sua vida e na prática profissional, que entra em contato com as variadas situações e vai se definindo e redefinindo por conta de sua conduta frente à morte. Nos cursos de graduação este tema ainda, mesmo que transversal e transdisciplinar, é incipiente.

Verificamos que os profissionais, muitas vezes se colocam no lugar dos pais ao se depararem com a criança em que se prestou cuidados, e que agora encontram-se no processo de morrer. Portanto, sobre sentimentos encontrados nos profissionais de enfermagem e da família quando lidam com a morte, a maioria está nivelada igualmente, o que foi identificado pelos pesquisadores como sentimentos negativos.

Temas como amparo profissional e registros sobre produções científicas em enfermagem descrevendo a temática morte ainda são pouco debatidos.

Concluiu-se que são necessários estudos futuros que problematizem a possível dissociáveis semântica entre o tema morte na enfermagem, assim como discutidos na formação, diversos assuntos como o nascimento e o desenvolvimento humano. Dessa maneira, será possível delinear novas perspectivas de estudos e intervenções sobre tal tema para que este comece a tomar maior relevância entre profissionais de enfermagem.

\section{REFERÊNCIAS}

1. Oliveira SG, Quintana AM, Bertolino KCO. Reflexões acerca da morte: um desafio para a enfermagem. Rev. bras. enferm. 2010; 63(6): 1077-80.

2. Salomé GM, Cavali A, Espósito VHC. Sala de Emergência: o cotidiano das vivências com a morte e o morrer pelos profissionais de saúde. Rev. bras. enferm. 2009; 62(5): 681-6. 
3. Poles K, Bousso RS. Compartilhando o processo de morte com a família: a experiência da enfermeira na uti pediátrica. Rev Lat Am Enfermagem. 2006; 14(2):20713.

4. Costa JC, Lima RAG. Luto da equipe: revelações dos profissionais de enfermagem sobre o cuidado à criança/adolescente no processo de morte e morrer. Rev Lat Am Enfermagem. 2005; 13(2):151-7.

5. Bolze DAS, Castoldi L. O acompanhamento familiar antes e depois da morte da criança: uma proposta de intervenção para o psicólogo hospitalar. Aletheia. 2005;21:7991.

6. Severino AJ. Metodologia do trabalho científico. 23 ${ }^{\text {a }}$ ed. São Paulo: Cortez; 2007.

7. Marconi MA, Lakatos EM. Fundamentos de metodologia científica. $7^{\mathrm{a}}$ ed. São Paulo: Atlas; 2010.

8. Poles K, Bousso RS. Morte digna da criança: análise de conceitos. Rev. Esc. Enferm. USP 2009; 43(1):215-22.

9. Oliveira JR, Brêtas JRS, Yamaguti L. A morte e o morrer segundo representações de estudantes de enfermagem. Rev. Esc. Enferm. USP 2007; 41(3):386-94.

10. Junior FJGS, Santos LCS, Moura PVS, Melo BMS, Monteiro CFS. Processo de morte e morrer: evidências da literatura científica de Enfermagem. Rev. bras. enferm. 2011; 64(6): 1122-6.

11. Nascimento LC, Rocha SMM, Hayes VH, Lima AG. Crianças com câncer e suas famílias. Rev. Esc. Enferm. USP 2005; 39(4):469-74.

12. Moreira PL, Angelo M. Tornar-se mãe de criança com câncer: construindo a parentalidade. Rev. Lat Am Enfermagem [periódico on line]. 2008; 16(3). Disponível em: http://www.scielo.br/pdf/rlae/v16n3/pt_04.pdf

13. Bousso RS, Serafim TS, Misko MD. Histórias de vida de familiares de crianças com doenças graves: relação entre religião, doença e morte. Rev. Latino-Am. Enfermagem [periódico on line]. 2007; 18(2) [7 telas]. Disponível em: http://www.scielo.br/pdf/rlae/v18n2/pt_03.pdf

14. Santos JL, Bueno SMV. Educação para a morte a docentes e discentes de enfermagem: revisão documental da literatura científica. Rev. Esc. Enferm. USP 2011; 45(1):272-6.

15. Bousso RS, Poles K, Serafim TS, Miranda MG. Crenças religiosas, doença e morte: perspectiva da família na experiência de doença. Rev. Esc. Enferm. USP 2011; 45(2):397-403.

16. Rio Grande do Sul. Ministério Público Rio Grande do Sul. Conselho Nacional dos Direitos da Criança e do Adolescente. Resolução no 41, de 17 de outubro de 1995. Aprova em sua íntegra o texto oriundo da Sociedade Brasileira de Pediatria, relativo aos 
Direitos da Criança e do Adolescente hospitalizados. [Internet]. Rio Grande do Sul; 1995. [acesso em: 09 abr. 2013]. Disponível em:

http://www.mp.rs.gov.br/infancia/legislacao/id2178.htm

17. São Paulo (Estado). Lei Estadual n 10.241, de 17 de março de 1999. Dispõe sobre os direitos dos usuários dos serviços e das ações de saúde no Estado e dá outras providências. [Internet]. São Paulo, SP; 1999. [acesso em: 09 abr. 2013]. Disponível em: http://www.pge.sp.gov.br/centrodeestudos/bibliotecavirtual/dh/volume\%20i/saudelei102 41.htm

18. Silva KS, Ribeiro RG, Kruse MHL. Discursos de enfermeiras sobre morte e morrer: vontade ou verdade? Rev. bras. enferm. 2009; 62(3): 451-6.

19. Bousso RS, Rossato LM. Desenvolvimento de conceitos: novas direções para a pesquisa em tanatologia e enfermagem. Rev. Esc. Enferm. USP. 2009; 43(Esp 2):13316.

20. Silva LCSP, Valença CN, Germano RM. Estudo fenomenológico sobre a vivência da morte em uma unidade de terapia intensiva neonatal. Rev. bras. enferm. 2010; 63(5): $770-4$.

21. Santana MTBM, Jorge MSB. Corpo próprio como experiência vivencial da enfermeira no cuidar do outro no processo de morrer. Rev Lat Am Enfermagem [periódico on line]. 2007; 15(3). Disponível em:

http://www.scielo.br/scielo.php?script=sci_arttext\&pid=S010411692007000300016\&ln $\mathrm{g}=\mathrm{en} \& \mathrm{nrm}=\mathrm{iso} \& \operatorname{lng}=\mathrm{en \# \text {nota1 }}$ 